\title{
Chemical Composition, Insecticidal and Mosquito Larvicidal Activities of Allspice (Pimenta dioica) Essential Oil
}

\author{
Arunaksharan Narayanankutty ${ }^{1, *(1)}$, Aswathi Moothakoottil Kuttithodi ${ }^{1}$, Ahmed Alfarhan ${ }^{2, *}$, \\ Rajakrishnan Rajagopal ${ }^{2}$ and Damia Barcelo ${ }^{3}$ D \\ 1 Division of Cell and Molecular Biology, PG and Research Department of Zoology, St. Joseph's \\ College (Autonomous), Devagiri, Calicut 673008, India; abcaswathi@gmail.com \\ 2 Department of Botany and Microbiology, College of Science, King Saud University, P.O. Box 2455, \\ Riyadh 11451, Saudi Arabia; rrajagopal@ksu.edu.sa \\ 3 Water and Soil Research Group, Department of Environmental Chemistry, IDAEA-CSIC, JORDI \\ GIRONA 18-26, 08034 Barcelona, Spain; damia.barcelo@idaea.csic.es \\ * Correspondence: arunaksharan1990@gmail.com (A.N.); alfarhan@ksu.edu.sa (A.A.); \\ Tel.: +91-9847-793-5278 (A.N.)
}

\section{check for} updates

Citation: Narayanankutty, A.; Kuttithodi, A.M.; Alfarhan, A.; Rajagopal, R.; Barcelo, D. Chemical Composition, Insecticidal and Mosquito Larvicidal Activities of Allspice (Pimenta dioica) Essential Oil. Molecules 2021, 26, 6698. https:// doi.org/10.3390/molecules26216698

Academic Editors: Eliza Oprea,

Carmen Chifiriuc and Vincenzo De Feo

Received: 17 September 2021

Accepted: 29 October 2021

Published: 5 November 2021

Publisher's Note: MDPI stays neutral with regard to jurisdictional claims in published maps and institutional affiliations.

Copyright: (c) 2021 by the authors. Licensee MDPI, Basel, Switzerland. This article is an open access article distributed under the terms and conditions of the Creative Commons Attribution (CC BY) license (https:// creativecommons.org/licenses/by/ $4.0 /)$.

\begin{abstract}
Essential oils are biologically and environmentally safe pesticidal compounds yielded from aromatic plants. Spices are important sources of essential oils, and they are widely used in the medicine, food, and various other industries. Among the different spices, Allspice (Pimenta dioica) is underexplored in terms of its biological efficacy and a limited number of studies are available on the chemical composition of Allspice essential oil (AEO); thus, the present study evaluated the larvicidal property, the repellency, and the fumigant toxicity against common pests of stored products of AEO. AEO was found to inhibit the survival of larvae of such vectors as Aedis, Culex, and Armigeres species. Further, AEO was found to exert repellant effects against the pests of such stored products as Sitophilus, Callosobruchus, and Tribolium. Similarly, the fumigant toxicity was found to be high for AEO against these species. The contact toxicity of AEO was high against Sitophilus and Callosobruchus. Apart from that, the essential oil was found to be safe against a non-target organism (guppy fishes) and was found to be non-genotoxic in an Allium cepa model. Overall, the results of the present study indicate that the essential oil from Allspice could be used as an environmentally safe larvicidal and biopesticidal compound.
\end{abstract}

Keywords: Pimenta dioica essential oil; larvicidal property; biopesticidal activity; Sitophilus oryzae; Callosobruchus maculatus

\section{Introduction}

Insects are important organisms that are known to be beneficial to humans in many respects, including nutrition, agriculture, and environmental stability. In contrast, several other insects are harmful in terms of health damage, crop damage, or even causing pollution. Among these, pests and vectors are the most destructive organisms and cause significant health damages and productivity losses. Insect pests cause severe damage to crops and products by feeding on the plant's parts or the stored cereals and pulses. Sitophilus sp., Tribolium sp., and Callosobruchus sp. are the most common insect pests of stored food materials such as cereals, grains, and pulses. Increased attacks from these pests often result in reduced productivity and, subsequently, a diminished economy [1]. Outbreaks of these pests often threaten global food security and, thereby, produce health concerns [2]. Apart from pests, vectors are another important group of insects comprised of mosquitos, ticks, and mites that have a significant impact on healthcare systems. Mosquitoes act as the prime vectors for the transmission of such pathogens as Zika virus, Plasmodium sp. (a malarial parasite), chikungunya virus, and dengue virus. The spread of mosquito-borne disease causes more than 400,000 deaths annually [3]. 
Taking into consideration the economic and agricultural losses caused by the different pests and the health risk posed by vectors, it is necessary to control vector and pest populations. Classical control measures, such as the application of an insecticide, have been capable of maintaining the population of these insects in check. Gradually, however, various insects gained resistance to these insecticides, thereby limiting the efficacy of control measures [4,5]. Apart from the limited efficacy, the environmental issues caused by insecticides and pest control agents constitute another emerging concern [6]. The various classes of pesticides have been proven to be phytotoxic to plants and also to the agriculture workers involved in their application [7,8]. In addition, cancer and neurotoxic effects are also common among individuals with chronic exposure to these chemical agents [9]. All this has led to an increase in the demand for biologically and environmentally safe molecules that can be used as pest-control and vector-control agents.

Essential oils have emerged as important agents that are capable of repelling and eliminating a variety of pests and vectors of human diseases. Essential oils extracted from traditionally used spices have a peculiar aroma and are reported to be superior to other essential oils from non-spice plants. It has therefore been suggested that integrated pest management techniques employing plant-derived essential oils could be a successful alternative to chemical pesticides and provide a better measure for pest control [10]. $\mathrm{Pi}$ menta dioica is such a spice plant and has been reported to have several health-promoting effects [11]. The preliminary studies by Rocha Voris et al. [12] have indicated the possible use of essential oil from $P$. dioica fruits against larvae and adults of Aedes sp. Furthermore, the essential oil was also found to inhibit the growth of Aspergillus and the production of alfatoxins by them [13]. It has also been reported that this essential oil acts as an antibacterial agent and was found to inhibit inflammation and edema conditions $[14,15]$. However, the essential oils of $P$. dioica leaves have yet to be evaluated in terms of their larvicidal and insecticidal potential; furthermore, no reports are available on their environmental toxicity. Hence, the assumption is that, by virtue of the bioactive components present, the Allspice ( $P$. dioica) essential oil (AEO) may exert significant growth inhibitory effects on mosquito larvae and common insect pests. Thus, this study evaluated the application of AEO in the control of mosquito larval and pest populations. In addition, the effect of AEO on non-targeted species, phytotoxicity, and an Allium cepa model of genotoxicity was also evaluated.

\section{Results}

\subsection{Average Yield of AEO and Its Chemical Characterization}

The Allspice essential oil obtained in this study was $1.02 \pm 0.08 \%$ in each of three independent preparations. Further, it was chemically characterized using GC-MS techniques. Eugenol (65.82\%) and its derivative methyl eugenol (15.22\%) were predominant in the essential oil. Additionally, caryophyllene, cineole, humulene, and terpinolene were observed in the Allspice essential oil (Table 1).

Table 1. GC-MS analysis of the essential oil extracted from Pimenta dioica leaves using steam distillation.

\begin{tabular}{cccc}
\hline S1. No. & Compound & Retention Index & \% $^{\mathbf{a}}$ \\
\hline 1 & $\alpha$-Thujene & 937 & 0.11 \\
2 & $\alpha$-Pinene & 946 & 0.06 \\
3 & $\beta$-Pinene & 986 & 0.15 \\
4 & Myrcene & 991 & 0.44 \\
5 & $\alpha$-Phellandrene & 1005 & 1.46 \\
6 & $\alpha$-Terpinene & 1020 & 0.08 \\
7 & p-Cymene & 1026 & 0.66 \\
8 & Ocimene & 1030 & 0.22 \\
9 & 1,8 -Cineole & 1033 & 1.86 \\
10 & $\gamma$-Terpinene & 1062 & 0.40 \\
11 & Terpinolene & 1092 & 1.05 \\
\end{tabular}


Table 1. Cont.

\begin{tabular}{cccc}
\hline S1. No. & Compound & Retention Index & $\mathbf{\%}^{\mathbf{a}}$ \\
\hline 13 & Linalool & 1098 & 0.05 \\
14 & trans- $p$-Menth-2,8-dien1-ol & 1108 & 0.10 \\
15 & cis- -Mentha-2,8-dien1-ol & 1120 & 0.01 \\
16 & $\beta$-Terpineol & 1180 & 0.66 \\
17 & $p$-Cymene-1-ol & 1185 & 0.18 \\
18 & Citronellol & 1220 & 0.46 \\
19 & Linalyl acetate & 1250 & 0.01 \\
20 & Terpinyl acetate & 1333 & 0.61 \\
21 & Eugenol & 1351 & 65.82 \\
22 & Methyl eugenol & 1401 & 15.22 \\
23 & Caryophyllene & 1428 & 4.03 \\
24 & $\beta$-Gurjunene & 1432 & 0.04 \\
25 & Aromadendrene & 1440 & 0.10 \\
26 & Alloaromadendrene & 1461 & 0.01 \\
27 & $\alpha$-Humulene & 1465 & 1.58 \\
28 & Cedrene & 1468 & 0.24 \\
29 & Bergamotene & 1470 & 0.06 \\
30 & $\gamma$-Muurolene & 1475 & 0.84 \\
31 & Patchulene & 1486 & 0.24 \\
32 & Germacrene D & 1490 & 0.49 \\
33 & $\beta$-Bisabolene & 1506 & 0.10 \\
34 & Caryophyllene oxide & 1566 & 0.61 \\
\hline
\end{tabular}

( ${ }^{a}$ Relative area $=$ relative content expressed as a percentage of the total oil composition).

\subsection{Lethality of AEO on the Different Mosquito Larval Forms}

The larvicidal activity of AEO over $24 \mathrm{~h}$ was found to be high against Aedes aegypti with a $\mathrm{LC}_{50}$ value of $18.5 \pm 1.2 \mu \mathrm{g} / \mathrm{mL}$ (Figure 1). Similarly, AEO was found to be effective against Culex quinquefasciatus and Armigeres subalbatus species, with respective $\mathrm{LC}_{50}$ values of $28.9 \pm 1.6$ and $55.1 \pm 3.1 \mu \mathrm{g} / \mathrm{mL}$. Among these, Aedes aegypti was the most sensitive to AEO, whereas the larvae of $A$. subalbatus were the most resistant. The $\mathrm{IC}_{50}$ values for $24 \mathrm{~h}$ and $48 \mathrm{~h}$ are listed in Supplementary Material Table S1.

\subsection{Potential Role of the Allspice Essential Oil in Eliminating Pests}

AEO was found to have anti-feedant activity against Sitophilus species $(1.57 \pm 0.09 \mu \mathrm{g} / \mathrm{g}$ of wheat flour). Likewise, the respective $\mathrm{IC}_{50}$ value against $T$. castaneum and $C$. maculatus was $2.04 \pm 0.10 \mu \mathrm{g} / \mathrm{g}$ and $1.88 \pm 0.06 \mu \mathrm{g} / \mathrm{g}$ (Table 2). In addition, significant repellant activity was also observed for AEO against the three pest species, the highest being against S. oryzae ( $3.79 \pm 0.18 \mu \mathrm{g} / \mathrm{L}$ of air). Supplementary Material Table S2 shows a comparison of the efficacy of a single dose of AEO against different pests for each level of biological activity.

The lethality of AEO was determined in terms of its fumigant potential as well as its contact toxicity. The respective $\mathrm{IC}_{50}$ values are shown in Table 2. AEO was the most effective against $S$. oryzae compared with the other pests. 

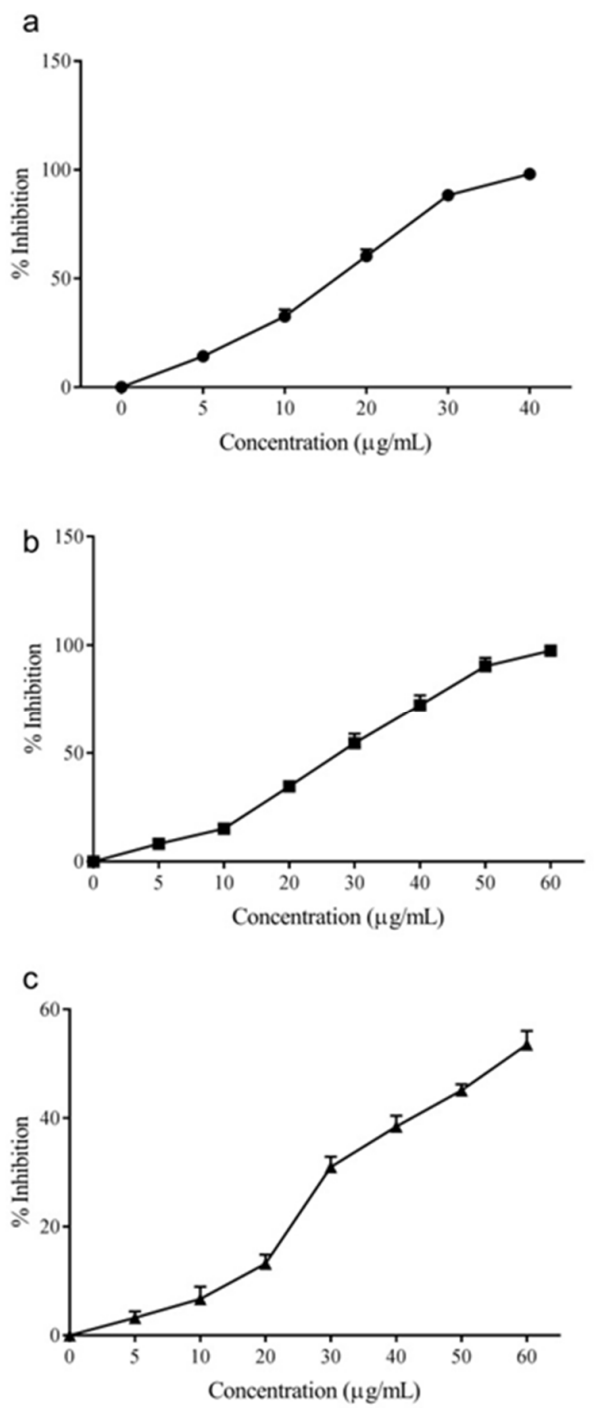

Figure 1. The larvicidal activity of Allspice essential oil against Aedes aegypti (a), Culex quinquefasciatus (b), and Armigeres subalbatus (c) larvae over $24 \mathrm{~h}$.

Table 2. The insecticidal properties of Pimenta dioica (Allspice) essential oil extracted by steam distillation estimated in terms of repellent efficacy, contact toxicity, and fumigant toxicity.

\begin{tabular}{ccc}
\hline Test & Assay & IC $_{\mathbf{5 0}}$ Values \\
\hline Anti-feedant assay & Sitophilus oryzae & $1.57 \pm 0.09$ \\
$\left(\mathrm{IC}_{50} \mu \mathrm{g} / \mathrm{g}\right.$ wheat flour $)$ & Tribolium castaneum & $2.04 \pm 0.10$ \\
& Callosobruchus maculatus & $1.88 \pm 0.06$ \\
\hline Repellent activity & Sitophilus oryzae & $3.79 \pm 0.18$ \\
$\mathrm{RC}_{50}$ & Tribolium castaneum & $5.38 \pm 0.22$ \\
$(\mu \mathrm{g} / \mathrm{L}$ of air $)$ & Callosobruchus maculatus & $5.15 \pm 0.31$ \\
\hline Fumigant toxicity & Sitophilus oryzae & $14.5 \pm 0.61$ \\
$\mathrm{LC}_{50}$ & Tribolium castaneum & $19.1 \pm 0.43$ \\
$(\mu \mathrm{g} / \mathrm{L}$ of air $)$ & Callosobruchus maculatus & $18.5 \pm 0.67$ \\
\hline Contact toxicity LD & Sitophilus oryzae & $75.1 \pm 3.08$ \\
$\left(\mu \mathrm{g} / \mathrm{mm}^{2}\right)$ & Tribolium castaneum & $81.6 \pm 2.04$ \\
\hline & Callosobruchus maculatus & $69.3 \pm 1.55$ \\
\hline
\end{tabular}




\subsection{Ecological Safety Analysis of AEO}

The ecological safety analysis of AEO was performed in terms of phytotoxicity, genotoxicity, and toxic effects on non-targeted organisms. As indicated in Table 3, we observed no significant variation in the germination potential of grains treated with AEO doses. Further, the treatment with AEO was found to remain non-toxic towards A. cepa mitotic events, and we did not observe any chromosomal damage to the tissue, even in A. cepa cells treated with the highest dose of AEO (Table 4). Similarly, the essential oil was not observed to induce any kind of behavioral changes in guppy fishes over a period of $48 \mathrm{~h}$ (Table 5) and at different time points (Supplementary Material Table S3). Hence, the results confirm that Allspice essential oil is safe in terms of germination potential, mitotic cell division, and non-targeted organism toxicity.

Table 3. Phytotoxic effect of Allspice (Pimenta dioica) essential oil in terms of the germination potential of wheat (\% germination).

\begin{tabular}{ccccc}
\hline \multirow{2}{*}{$\begin{array}{c}\text { Duration of Exposure } \\
\text { in Hours }\end{array}$} & Untreated & \multicolumn{3}{c}{$\begin{array}{c}\text { Pimenta dioica Essential Oil } \\
(\boldsymbol{\mu g} / \mathbf{m L})\end{array}$} \\
\cline { 3 - 5 } & Grains & $\mathbf{1 0 0}$ & $\mathbf{2 5 0}$ & $\mathbf{5 0 0}$ \\
\hline 48 & $14.1 \pm 2.4$ & $13.8 \pm 1.4$ & $13.4 \pm 1.2$ & $13.5 \pm 2.0$ \\
72 & $32.6 \pm 1.3$ & $33.4 \pm 1.6$ & $32.1 \pm 1.5$ & $32.9 \pm 1.1$ \\
96 & $60.2 \pm 2.4$ & $58.6 \pm 2.1$ & $58.4 \pm 2.4$ & $59.1 \pm 1.9$ \\
120 & $82.1 \pm 3.2$ & $80.6 \pm 3.0$ & $79.2 \pm 3.1$ & $80.5 \pm 2.4$ \\
144 & $92.6 \pm 1.1$ & $90.2 \pm 3.3$ & $91.3 \pm 2.4$ & $91.4 \pm 2.3$ \\
\hline
\end{tabular}

Table 4. Genotoxicity assay of Allspice essential oil (AEO) in model Allium cepa mitotic cells.

\begin{tabular}{ccc}
\hline Treatment Group & Mitotic Index (\%) & Frequency of Aberrant Cells (\%) \\
\hline Normal $($ Untreated $)$ & $12.56 \pm 0.32$ & $0.42 \pm 0.03$ \\
AEO $(1 \mathrm{mg} / \mathrm{mL})$ & $12.41 \pm 0.17$ & $0.50 \pm 0.05$ \\
AEO $(2.5 \mathrm{mg} / \mathrm{mL})$ & $11.88 \pm 0.41$ & $0.51 \pm 0.07$ \\
AEO $(5 \mathrm{mg} / \mathrm{mL})$ & $12.01 \pm 0.40$ & $0.48 \pm 0.03$ \\
AEO $(10 \mathrm{mg} / \mathrm{mL})$ & $12.37 \pm 0.22$ & $0.51 \pm 0.08$ \\
\hline
\end{tabular}

Table 5. Toxicity analysis of Allspice essential oil (AEO) against a non-targeted organism (guppy fishes) at different doses.

\begin{tabular}{ccccc}
\hline Treatment Group & \% Mortality & $\begin{array}{c}\text { Fishes Having } \\
\text { Difficulty Swimming }\end{array}$ & $\begin{array}{c}\text { Fishes with a Color } \\
\text { Change }\end{array}$ & $\begin{array}{c}\text { Time Spent on Top of the Water } \\
\text { (Seconds) }\end{array}$ \\
\hline Normal & 0 & 0 & 0 & $31.2 \pm 4.0$ \\
AEO $(50 \mu \mathrm{g} / \mathrm{mL})$ & 0 & 0 & 0 & $37.6 \pm 2.0$ \\
$\mathrm{AEO}(100 \mu \mathrm{g} / \mathrm{mL})$ & 0 & 0 & 0 & $38.3 \pm 4.0$ \\
$\mathrm{AEO}(200 \mu \mathrm{g} / \mathrm{mL})$ & 0 & 0 & 0 & $30.5 \pm 5.0$ \\
$\mathrm{AEO}(250 \mu \mathrm{g} / \mathrm{mL})$ & 0 & 0 & 0 & $34.2 \pm 4.0$ \\
\hline
\end{tabular}

\section{Discussion}

Stress volatiles from plants are important chemicals known to be highly active in different aspects of biological assays. A considerable number of these stress volatiles are essential oils. These essential oils are known to have antimicrobial, anti-edematous, antioxidant, anti-proliferative, and antidiabetic activities. However, the most important attribute of an essential oil is its ability to regulate insect and larval populations. This study therefore evaluated the ability of a well-known spice-Allspice $(P$. dioica $)$ - to eliminate the larvae of different mosquito species as well as insect pests in stored food materials.

The results indicate the presence of eugenol and its derivative in the essential oil of Allspice leaves. Furthermore, molecules such as caryophyllene and cineole were identified in the AEO. Previous studies by Rocha Voris et al. [12] and Chaudhari et al. [13] also found a large amount of eugenol in the essential oil extracted from buds and bark of Allspice. 
These studies were also indicative of the larvicidal properties of the essential oil from Allspice. Supporting their findings, we also observed significant larvicidal activity against the various mosquito species, and AEO exhibited the highest activity against the Aedes species. Aedes species are distributed globally and have been reported to act as vectors of arboviral diseases [16], Chikungunya virus [17], dengue virus [18], and the recent Zika viral diseases [19]. Therefore, controlling the larval population of Aedes species by AEO may help to prevent the spread of these diseases considerably. It has previously been reported that eugenol and its derivatives have significant larvicidal properties against a wide variety of mosquitoes $[20,21]$. Furthermore, the application of pesticides to control larval populations has raised concerns about non-targeted organism toxicities; however, the present study confirmed the non-toxic nature of AEO against guppy fishes as a model. Hence, this result suggests that AEO is a potential larvicidal candidate with low non-targeted organism toxicity, which makes it preferable over synthetic and chemical insecticides.

In connection with these, AEO has been found to be effective as an anti-feedant and a repellent agent against different pests that are common in stored cereals and pulses. These pests are known to cause significant losses in productivity and to the economy by damaging the stored food materials. Hence, the control of their population by AEO has great potential to improve the storage quality of food materials. In addition, AEO was found to significantly increase the mortality rate in these pests as a fumigant and contact insecticide. The fumigant potential is more influential as it can reach even the smaller areas of storage packets or storage houses. The predominant compound in AEO, eugenol, has been shown to exert an anti-feedant effect on the red palm weevil [22]; likewise, it was found to be a strong insecticide against Sitophilus species [23]. Recent studies have also indicated that synthetic derivatives of eugenol can be an alternative to chemical insecticides [24].

In addition to these findings, the study also confirmed the safety of AEO. It was observed that AEO is not toxic to germinating seeds, even at its highest doses. This widens the range of possible uses of AEO as an insecticide, even for areas of seed storage. Furthermore, there was no sign of genotoxic activity in the A. cepa model analyzed. Overall, AEO could be a suitable non-toxic or ecologically safe alternative to chemical pesticides.

\section{Materials and Methods}

\subsection{Collection, Extraction, and Chemical Composition Analysis of Allspice (P. dioica) Leaf Essential Oil}

Pimenta dioica leaves (other than tender leaves) were collected from the Kozhikode district during the August-September period and authenticated by Dr. Anisha M Sathyan, Botanist, Malabar Christian College, Kerala, India. The leaves were cleaned to remove the dust, refrigerated at $-80{ }^{\circ} \mathrm{C}$ (Remi, Mumbai, India), and powdered using a mortar. A hydro-distillation technique was employed for the extraction of essential oil. The extraction was carried out in three independent isolations and the yield and composition of each were recorded. The extraction procedure and storage were carried out according to the methods described by Chaverri and Cicció [25] without significant modifications.

The chemical nature of the obtained essential oil was determined by the gas chromatography-mass spectroscopy (Shimadzu, Kyoto, Japan) technique described in the previous published reports of Lorenzo-Leal, Palou, and López-Malo [26]. The chemical nature was predicted from the chromatogram using the retention index and the $\mathrm{m} / \mathrm{z}$ ratio and by comparison with the standard NIST library.

\subsection{Efficacy of Pimenta dioica Essential Oil against Mosquito Larvae}

The mosquito larvicidal activity was determined according to the methods described by Hung et al. [27]. The mosquito species selected for the study included Aedes aegypti, Culex quinquefasciatus, and Armigeres subalbatus species. The mosquitoes were grown in separate insect cages for 10 generations. The larvae of each species were reared and were collected at their third instar state for experimental purposes. About 50 larvae of each 
mosquito species were placed in $500 \mathrm{~mL}$ beakers and varying doses of the essential oil were dissolved in them. The larvae in each bottle were observed for $24 \mathrm{~h}$ and the mortality rate was recorded on time. The percentage mortality of AEO was determined by comparison to a normal control at the end of a 24-h period.

\subsection{Allspice Essential Oil (AEO) and Pest Control Capacity}

\subsubsection{Anti-Feedant Activity of AEO on Wheat Flour}

The anti-feedant activity of AEO was determined according to the methods described by Zhang et al. [28]. The percentage inhibition of wheat flour intake was estimated by comparing the consumption of an AEO and wheat flour mixture with that of wheat flour without AEO. For the anti-feedant assay, the sample size used per group was 25 pests.

\subsubsection{Repellant Activity}

The repellant potential of essential oils is important to the management of pests. This study employed the protocol discussed by Patiño-Bayona et al. [20]. The repellency was estimated as the ability of AEO to displace the insects from an essential-oil-exposed bottle to an untreated bottle and the median repellant dose is expressed as $\mu \mathrm{g} / \mathrm{L}$ of air. Twenty-five pests per group were selected for the repellency assays.

\subsubsection{AEO as A Potential Fumigant Agent}

The toxicity of AEO as a fumigant agent against the different pests was estimated by the protocols laid down by Patiño-Bayona et al. [29]. The activity was determined as the lethal dose of $\mathrm{AEO}$ as a fumigant and is expressed as the $\mathrm{LC}_{50}$ value in $\mu \mathrm{g} / \mathrm{L}$ of air. The fumigant potential was assessed using a sample size of 25 pests per treatment group.

\subsubsection{Determination of AEO's Contact Toxicity}

AEO at different doses was applied to adult insects in their pro-thorax region according to the methods of Paventi et al. [30]. The untreated and essential-oil-treated insects were observed for $48 \mathrm{~h}$ continuously, and the lethality and lethal concentration (the $\mathrm{LD}_{50}$ value) were determined. For the contact toxicity tests, 50 pests were chosen per treatment group.

\subsection{Allspice Essential Oil and Its Effect on the Germination Potential of Grains}

The effect of AEO on grain seed germination is considered to be an indicator of its phytotoxicity. The analysis was carried out as per the studies of Ibáñez and Blázquez [31]. The wheat grains (20 nos) were allowed to germinate in the presence and absence of AEO for 6 days. Protrusion of a well-developed radicle from the grain with a length of $1 \mathrm{~cm}$ was considered to be an indication of germination.

\subsection{Non-Targeted Species Toxicity in Guppy Fish (Poecilia reticulata)}

The guppy fish (Poecilia reticulata) is widely known for its insectivorous nature, especially with respect to the larvae of mosquitos. Hence, these fish are threatened during the application of a toxic agent against mosquito larvae. So, the species is an apt non-target organism. Fishes (with a length of $3.05 \pm 0.11 \mathrm{~cm}$ and a body weight of $1.08 \pm 0.09 \mathrm{~g}$ ) were exposed to different doses of AEO for $48 \mathrm{~h}$ and observed continuously for signs of toxicity [32].

\subsection{AEO's Genotoxic Effect on an Allium Cepa Model of Mitotic Damage}

A. cepa bulbs with a uniform weight were selected and planted in individually compartmentalized plates and allowed to grow in the presence of varying concentrations of AEO for $72 \mathrm{~h}$. A set of compartments were left untreated and were considered a control. At the end of the 72-h period, the actively dividing portions of each onion bulb were collected and fixed, and a smear was prepared [33]. The mitotic index, sticky and bridged chromosomes, and the presence of micronuclei were analyzed microscopically. 


\subsection{Statistical Analysis}

The essential oil's preparation was carried out three times and the mean and SD of the three independent experiments are presented. All other bioassays were repeated five times. The statistical tool employed was one-way ANOVA followed by Tukey's test using GraphPad Prism version 7.00 (La Jolla, CA, USA).

\section{Conclusions}

The Allspice (P. dioica) leaf essential oil was found to be beneficial in the prevention of the growth of mosquito larvae and to thereby be a promising candidate for mosquito eradication. Furthermore, we observed AEO to have significant anti-feedant and repellent abilities, which again emphasize its possible pest-repellent properties. Lethality to different pests was also observed, suggesting that AEO could be used as a fumigant and contact insecticide. These results suggest the use of AEO for the possible elimination of pests by repelling as well as by killing pests. In addition, the essential oil was also found to be safe towards germinating grains, cellular division, the genome, and non-targeted animal species. We therefore conclude that AEO could be an ecologically safe insecticide and larvicide.

Supplementary Materials: The following are available online. Table S1: Larvicidal potential of Allspice (Pimenta dioica) essential oil at different time points of treatment; the efficacy has been expressed as the half-maximal lethal concentration $\left(\mathrm{LC}_{50}\right)(\mu \mathrm{g} / \mathrm{mL})$, Table S2: Insecticidal property of Allspice essential oil at a specific dose over different time points on insects pests, Table S3: Effect of Allspice essential oil against non-target organism at varying doses over different time periods.

Author Contributions: A.N.: Study design, Methodology, Analysis, Manuscript Editing; A.M.K.: Experimentation, Analysis; Manuscript Draft preparation; A.A.: Study Design, Methodology, Fund acquisition, Manuscript editing; R.R.: Analysis, Manuscript preparation, Manuscript Editing; D.B.: Study design, Funding acquisition, Manuscript Editing. All authors have read and agreed to the published version of the manuscript.

Funding: This study was supported by King Saud University, Riyadh, Saudi Arabia through Researchers Supporting Project No: RSP 2021/11. Infrastructural development was supported by DBT-STAR to St. Joseph's College, Devagiri, Calicut.

Institutional Review Board Statement: Not applicable.

Informed Consent Statement: Not applicable.

Data Availability Statement: The data may be shared upon a valid request.

Acknowledgments: The authors acknowledge King Saud University, Riyadh, Saudi Arabia for funding this research through Researchers Supporting Project No: RSP 2021/11. A.N. acknowledges the DBT-STAR scheme for infrastructural development at St. Joseph's College, Devagiri, Calicut.

Conflicts of Interest: The authors declare no conflict of interest.

Sample Availability: Samples of the compounds are available from the corresponding author.

\section{References}

1. Yaseen, M.; Kausar, T.; Praween, B.; Shah, S.J.; Jan, Y.; Shekhawat, S.S.; Malik, M.; Azaz Ahmad Azad, Z.R. Insect Pest Infestation During Storage of Cereal Grains, Pulses and Oilseeds, In Health and Safety Aspects of Food Processing Technologies, Health and Safety Aspects of Food Processing Technologies; Malik, A., Erginkaya, Z., Erten, H., Eds.; Springer International Publishing: Cham, Switzerland, 2019; pp. 209-234.

2. Wyckhuys, K.A.G.; Lu, Y.; Zhou, W.; Cock, M.J.W.; Naranjo, S.E.; Fereti, A.; Williams, F.E.; Furlong, M.J. Ecological pest control fortifies agricultural growth in Asia-Pacific economies. Nat. Ecol. Evol. 2020, 4, 1522-1530. [CrossRef] [PubMed]

3. Prudêncio, M. In Fairness to Mosquitoes. Trends Parasitol. 2020, 36, 876-877. [CrossRef] [PubMed]

4. Dang, K.; Doggett, S.L.; Singham, G.V.; Lee, C.-Y. Insecticide resistance and resistance mechanisms in bed bugs, Cimex spp. (Hemiptera: Cimicidae). Parasites Vectors 2017, 10, 1-31. [CrossRef] [PubMed]

5. Gan, S.J.; Leong, Y.Q.; Bin Barhanuddin, M.F.H.; Wong, S.T.; Wong, S.F.; Mak, J.W.; Ahmad, R.B. Dengue fever and insecticide resistance in Aedes mosquitoes in Southeast Asia: A review. Parasites Vectors 2021, 14, 315. [CrossRef] [PubMed] 
6. Gunstone, T.; Cornelisse, T.; Klein, K.; Dubey, A.; Donley, N. Pesticides and Soil Invertebrates: A Hazard Assessment. Front. Environ. Sci. 2021, 9, 643847. [CrossRef]

7. Giménez-Moolhuyzen, M.; Blom, J.v.d.; Lorenzo-Mínguez, P.; Cabello, T.; Crisol-Martínez, E. Photosynthesis Inhibiting Effects of Pesticides on Sweet Pepper Leaves. Insects 2020, 11, 69. [CrossRef]

8. Hassaan, M.A.; El Nemr, A. Pesticides pollution: Classifications, human health impact, extraction and treatment techniques. Egypt J. Aquat. Res. 2020, 46, 207-220. [CrossRef]

9. Nicolopoulou-Stamati, P.; Maipas, S.; Kotampasi, C.; Stamatis, P.; Hens, L. Chemical Pesticides and Human Health: The Urgent Need for a New Concept in Agriculture. Front. Public Health 2016, 4, 148. [CrossRef]

10. Birch, A.N.E.; Begg, G.S.; Squire, G.R. How agro-ecological research helps to address food security issues under new IPM and pesticide reduction policies for global crop production systems. J. Exp. Bot. 2011, 62, 3251-3261. [CrossRef]

11. Zhang, L.; Lokeshwar, B.L. Medicinal properties of the Jamaican pepper plant Pimenta dioica and Allspice. Curr. Drug Targets 2012, 13, 1900-1906. [CrossRef]

12. Gomes da Rocha Voris, D.; dos Santos Dias, L.; Alencar Lima, J.; dos Santos Cople Lima, K.; Pereira Lima, J.B.; dos Santos Lima, A.L. Evaluation of larvicidal, adulticidal, and anticholinesterase activities of essential oils of Illicium verum Hook. f., Pimenta dioica (L.) Merr. and Myristica fragrans Houtt. against Zika virus vectors. Environ. Sci. Pollut. Res. 2018, 25, 22541-22551. [CrossRef]

13. Chaudhari, A.K.; Singh, V.K.; Dwivedy, A.K.; Das, S.; Upadhyay, N.; Singh, A.; Dkhar, M.S.; Kayang, H.; Prakash, B.; Dubey, N.K. Chemically characterised Pimenta dioica (L.) Merr. essential oil as a novel plant based antimicrobial against fungal and aflatoxin B(1) contamination of stored maize and its possible mode of action. Nat. Prod. Res. 2020, 34, 745-749. [CrossRef] [PubMed]

14. Lorenzo-Leal, A.C.; Palou, E.; López-Malo, A.; Bach, H. Antimicrobial, Cytotoxic, and Anti-Inflammatory Activities of Pimenta dioica and Rosmarinus officinalis Essential Oils. BioMed Res. Int. 2019, 2019, 1639726. [CrossRef]

15. Mérida-Reyes, M.S.; Muñoz-Wug, M.A.; Oliva-Hernández, B.E.; Gaitán-Fernández, I.C.; Simas, D.L.R.; Ribeiro da Silva, A.J.; Pérez-Sabino, J.F. Composition and Antibacterial Activity of the Essential Oil from Pimenta dioica (L.) Merr. from Guatemala. Medicines 2020, 7, 59. [CrossRef] [PubMed]

16. Weetman, D.; Kamgang, B.; Badolo, A.; Moyes, C.L.; Shearer, F.M.; Coulibaly, M.; Pinto, J.; Lambrechts, L.; McCall, P.J. Aedes Mosquitoes and Aedes-Borne Arboviruses in Africa: Current and Future Threats. Int. J. Environ. Res. Public Health 2018, 15, 220. [CrossRef]

17. Aragão, C.F.; Pinheiro, V.C.S.; Neto, J.P.N.; Da Silva, E.V.P.; Pereira, G.J.G.; Nascimento, B.L.S.D.; Castro, K.D.S.; Maia, A.M.; Catete, C.P.; Martins, L.C.; et al. Natural Infection of Aedes aegypti by Chikungunya and Dengue type 2 Virus in a Transition Area of North-Northeast Brazil. Viruses 2019, 11, 1126. [CrossRef] [PubMed]

18. Gloria-Soria, A.; Armstrong, P.M.; Powell, J.R.; Turner, P.E. Infection rate of Aedes aegypti mosquitoes with dengue virus depends on the interaction between temperature and mosquito genotype. Proc. R. Soc. B Boil. Sci. 2017, 284, 20171506. [CrossRef]

19. Mourya, D.T.; Gokhale, M.D.; Majumdar, T.D.; Yadav, P.D.; Kumar, V.; Mavale, M.S. Experimental Zika virus infection in Aedes aegypti: Susceptibility, transmission \& co-infection with dengue \& chikungunya viruses. Indian J. Med Res. 2018, 147, 88-96. [CrossRef] [PubMed]

20. Da Silva, B.C.; Melo, D.R.; Franco, C.T.; Maturano, R.; Fabri, R.L.; Daemon, E. Evaluation of Eugenol and (E)-Cinnamaldehyde Insecticidal Activity Against Larvae and Pupae of Musca domestica (Diptera: Muscidae). J. Med. Èntomol. 2019, 57, 181-186. [CrossRef]

21. Barbosa, J.D.; Silva, V.B.; Alves, P.B.; Gumina, G.; Santos, R.L.; Sousa, D.P.; Cavalcanti, S.C. Structure-activity relationships of eugenol derivatives againstAedes aegypti(Diptera: Culicidae) larvae. Pest Manag. Sci. 2012, 68, 1478-1483. [CrossRef] [PubMed]

22. Yan, T.; Asari, A.; Salleh, S.; Azmi, W. Eugenol and Thymol Derivatives as Antifeedant Agents against Red Palm Weevil, Rhynchophorus ferrugineus (Coleoptera: Dryophthoridae) Larvae. Insects 2021, 12, 551. [CrossRef] [PubMed]

23. Huang, Y.; Ho, S.-H.; Lee, H.-C.; Yap, Y.-L. Insecticidal properties of eugenol, isoeugenol and methyleugenol and their effects on nutrition of Sitophilus zeamais Motsch. (Coleoptera: Curculionidae) and Tribolium castaneum (Herbst) (Coleoptera: Tenebrionidae). J. Stored Prod. Res. 2002, 38, 403-412. [CrossRef]

24. Fernandes, M.J.G.; Pereira, R.B.; Pereira, D.M.; Fortes, A.G.; Castanheira, E.M.S.; Gonçalves, M.S.T. New Eugenol Derivatives with Enhanced Insecticidal Activity. Int. J. Mol. Sci. 2020, 21, 9257. [CrossRef] [PubMed]

25. Chaverri, C.; Cicció, J.F. Leaf and fruit essential oil compositions of Pimenta guatemalensis (Myrtaceae) from Costa Rica. Rev. Biol. Trop. 2014, 63, 303-311. [CrossRef]

26. Lorenzo-Leal, A.C.; Palou, E.; López-Malo, A. Evaluation of the efficiency of allspice, thyme and rosemary essential oils on two foodborne pathogens in in-vitro and on alfalfa seeds, and their effect on sensory characteristics of the sprouts. Int. J. Food Microbiol. 2019, 295, 19-24. [CrossRef]

27. Huy Hung, N.; Ngoc Dai, D.; Satyal, P.; Thi Huong, L.; Thi Chinh, B.; Quang Hung, D.; Anh Tai, T.; Setzer, W.N. Lantana camara Essential Oils from Vietnam: Chemical Composition, Molluscicidal, and Mosquito Larvicidal Activity. Chem. Biodivers. 2021, 18, e2100145. [CrossRef]

28. Zhang, W.; Wang, Y.; Geng, Z.; Guo, S.; Cao, J.; Zhang, Z.; Pang, X.; Chen, Z.; Du, S.; Deng, Z. Antifeedant Activities of Lignans from Stem Bark of Zanthoxylum armatum DC. against Tribolium castaneum. Molecules 2018, 23, 617. [CrossRef] [PubMed] 
29. Patiño-Bayona, W.R.; Nagles Galeano, L.J.; Bustos Cortes, J.J.; Delgado Ávila, W.A.; Herrera Daza, E.; Suárez, L.E.C.; PrietoRodríguez, J.A.; Patiño-Ladino, O.J. Effects of Essential Oils from 24 Plant Species on Sitophilus zeamais Motsch (Coleoptera, Curculionidae). Insects 2021, 12, 532. [CrossRef]

30. Paventi, G.; Rotundo, G.; Pistillo, M.; D'Isita, I.; Germinara, G. Bioactivity of Wild Hop Extracts against the Granary Weevil, Sitophilus granarius (L.). Insects 2021, 12, 564. [CrossRef]

31. Ibáñez, M.D.; Blázquez, M.A. Phytotoxicity of Essential Oils on Selected Weeds: Potential Hazard on Food Crops. Plants 2018, 7, 79. [CrossRef]

32. Bullangpoti, V.; Mujchariyakul, W.; Laksanavilat, N.; Junhirun, P. Acute toxicity of essential oil compounds (thymol and 1,8-cineole) to insectivorous guppy, Poecilia reticulata Peters, 1859. Agric. Nat. Resour. 2018, 52, 190-194. [CrossRef]

33. Owolarafe, T.A.; Salawu, K.; Ihegboro, G.O.; Ononamadu, C.J.; Alhassan, A.J.; Wudil, A.M. Investigation of cytotoxicity potential of different extracts of Ziziphus mauritiana (Lam) leaf Allium cepa model. Toxicol. Rep. 2020, 7, 816-821. [CrossRef] [PubMed] 